\title{
A Conversation with Marisa Bartolomei
}

\author{
INTERVIEWER: Beth MOOREFIELD
}

Senior Editor, Nature Structural and Molecular Biology

\begin{abstract}
Marisa Bartolomei is a Professor in the Department of Cell and Developmental Biology and Co-Director of the Epigenetics Institute, University of Pennsylvania Perelman School of Medicine, Philadelphia, Pennsylvania.
\end{abstract}

Beth Moorefield: You study a unique process of gene expression in mammalian cells known as genomic imprinting, which directs expression specifically from either maternal or paternal alleles. I thought we could speak about the function of the imprinted genes and the mechanisms that govern their regulation.

Dr. Bartolomei: Imprinting is a mammalian phenomenon, and it affects $\sim 100-200$ genes. It's nicely conserved in mammals, which gives us the opportunity to use mouse as a good model to study imprinting in humans. These genes have very important processes in growth, but they also have functions in postnatal energy homeostasis, in behavior, and in other processes. So, when these genes are missing or defective, you end up with very broad changes - broad sorts of imprinting disorders - if there are defects in humans. That would include BeckwithWiedemann or Silver-Russell syndromes - those are growth imprinting disorders - or Angelman and PraderWilli syndromes, and those are neurobehavioral disorders. So they have a broad range of functions, and absence of these genes causes these disorders, which is why we want to really understand their regulation.

Beth Moorefield: Are the maternal or paternal alleles imprinted with equal frequency, or is there a bias toward one or the other?

Dr. Bartolomei: These imprinted genes are regulated by regions that we call "imprinting control regions." These imprinting control regions are discrete elements in the genome that experience epigenetic modifications, so they have DNA methylation that's put on either during male or female gametogenesis. If you look at these regions, there are many more of these methylated imprinting-control regions that come from the female germline, and just a few in the male germline, so a lot of the action seems to be happening in the female germline. That said, these imprinted genes are found in large clusters through the genome and they seem to be pretty well equally represented as maternally expressed imprinted genes and paternally expressed imprinted genes. There doesn't seem to be a bias in that sense.
Beth Moorefield: How would they distinguish either of these alleles? How are they identified as maternal or paternal so that they're differentially recognized by the transcriptional machinery?

Dr. Bartolomei: That's the question. We know that these differential epigenetic modifications that are put on in the germline are what helps us to say, "If this comes from the maternal allele, either express or repress off the maternal allele," or modifications that are put on in the paternal germline help us to recognize something as being paternal and either expressed or repressed. These germline modifications are actually key to allowing the somatic cells to say, "Maternal, express; paternal, repress," or vice versa. These modifications that are put on in the germline are really the key to the imprinting. When something is perturbed, that's when you see dysregulation of imprinted genes, and that can occur in the germline, or it also can occur postfertilization.

Beth Moorefield: Do each of the alleles share common regulatory elements themselves?

Dr. Bartolomei: When imprinted genes were first identified $\sim 25$ years ago, there actually were three imprinted genes that were published in the same year: IGF-2 (Insulin-like Growth Factor 2), Insulin-like Growth Factor 2 Receptor, and H19, which encodes a noncoding RNA. It was thought that these imprinted genes were going to contain this primary sequence that was identified either in the male or the female germline and that was what was going to be the key to imprinting. In fact, we thought there was going to be a "silver bullet": "We're going to identify the imprinting box!"... like the TATA box, there was an "imprinting box." It was going to be a simple sequence. But there is no such simple sequence, so maybe there's something more complex that we just haven't figured out with secondary structure or some other kind of sequence. Each imprinted region, each imprinted gene, seems to have a different type of control sequence that does different things and we really don't know what that specific signal is that says, "This is going to be an imprinted gene and this is not going to be an imprinted gene." We

(C) 2017 Bartolomei. This article is distributed under the terms of the Creative Commons Attribution-NonCommercial License, which permits reuse and redistribution, except for commercial purposes, provided that the original author and source are credited. 
have little bits and pieces, but the absolute mechanism hasn't been worked out completely.

Beth Moorefield: Are there actually affected areas? The ones that are differentially modified, are they always in the same position within these alleles or within the different genes themselves?

Dr. Bartolomei: That gets a little bit to the mechanism. The real central piece of imprinting, these imprinting control regions or ICRs, those are the ones that have the methylation put on either in the male or female germline and it's maintained as long as imprinting is maintained. There're two regions that people where these ICRs can be found. One is intergenic - so, in between genes - and the other is actually in promoters. Often, it's in the promoters of long noncoding RNAs. One of the first uses that was found for long noncoding RNAs was that their transcription drove imprinting genes in cis. The methylation is in the promoter and if it's highly methylated, the long noncoding RNA is not made. If it's unmethylated, it is made. That's an example of how these imprinting control regions are not only giving you maternal- or paternal-like differentiation, but also functioning to do something.

The intergenic imprinting control regions are a little different. For the ones that I study, H19 and IGF-2, the imprinting control region is actually an insulator region and it binds CTCF. When it's unmethylated, CTCF binds and it helps to confer the imprinting of the region. When it's methylated, CTCF can't bind, so there's no insulator formed. These ICRs have these two sorts of broad functions. There are other mechanisms involved, but these are the two main functions.

Beth Moorefield: If you have the differential pattern, how does it actually get propagated to the daughter cells upon division?

Dr. Bartolomei: When the methylation is put on in the germline, it's through the de novo DNA methyltransferases. It's likely that differential chromatin modifications are involved too, but the propagation is through the maintenance methyltransferase, DNMT1. It's actually one of the first experiments done by the Jaenisch laboratory showing that in the absence of DNMT1, there was failure to maintain imprinting. As the cells divide, DNMT1 migrates with the replication fork and puts the methylation on the newly replicated strands so that the imprints are maintained. The key for imprinting is that it's epigenetically maintained. It's maintained throughout the life of the organism, in most cases.

Beth Moorefield: Not only maintenance but also the modifications have to be reversed to permit germline development: How is that accomplished?

Dr. Bartolomei: The mammalian embryo is very interesting in that there are two major times in development when there is this very large-scale reprogramming that occurs. The first time is after fertilization. The gametes come in with their own methylation patterns, and there is reprogramming as these cells are going to become pluripotent.
At that time, imprints are maintained. There is something very special about them that enables that differential methylation to be maintained.

With mammals, as the embryo develops, the germline is set aside from the somatic cells. At early postimplantation, some cells that are recruited from the somatic cells, based on their location, are going to go on to form the germline. What happens there is then there is a second time of reprogramming. In that case, everything that will be reprogrammed is reprogrammed, including imprinting control regions. That's because if you're taking the germline from somatic cells that have maternal imprints and paternal imprints and you're going to become a germ cell in a female, you want to erase the maternal and paternal imprints and put on the maternal imprints; if you're in a male, you erase those and put on paternal imprints. That reprogramming occurs as the primordial germ cells are being specified and are replicating and migrating to enter the genital ridge.

Because a lot of methylation is lost at that timeDNMT1 is down-regulated and moved outside the nucleus for the most part - it was originally thought that what would happen is that the cells would replicate and there wouldn't be maintenance methylation. You would have a passive loss of methylation: Things would be diluted out, they enter the genital ridge, and they're remethylated. We know now that sometimes the demethylation is faster. In the last 10 years, a whole new mechanism of demethylation has been described through the TET enzymes. It's a family of three enzymes that will oxidize methylcytosines - TET1, -2, and -3-TET1 and -2 are expressed at the time when the methylation imprints are being erased. What we, and others, have shown now is that in the absence of TET1, some germ cells fail to erase all of the DNA methylation imprints; others do it fine. It seems that active and passive methylation are working together to reprogram, to erase imprints. In some pools of germ cells, we see a lot of remaining methylation; some, we see hardly any. We don't really understand what's going on in that case. The more you dig, the more mysteries you find in this field.

It's really an incredibly exciting field, a lot to be learned. That's still the basis of on-going research. Why is it? Why is it that we need two mechanisms, an active and a passive? Are they redundant? Are they helping each other? Are there some regions of the genome that are just so densely methylated, have such high affinity for DNMTs, that you need this extra mechanism in place to demethylate? We don't know yet, and we'd like to really learn that.

Beth Moorefield: It's not clear yet whether or not the residual methylation is actually precluding the de novo methylation events or what the functional interactions might be there?

Dr. Bartolomei: We do know that if we look at TET mutants that come from female and we look at maternally methylated regions that we would expect to be methylated in oocytes, they're methylated fine, but if we look at paternally methylated regions that should be unmethylated 
in oocytes, they are not. Sometimes they're still methylated; sometimes they're not. It doesn't look like residual methylation - whatever might be happening - is preventing de novo methylation from occurring. That's only looking at early in development and later in development. We don't know what's happening in between. If we could liveimage cells... There's always this "on-paper experiment" you can think about where you could follow a cell and see demethylation occurring at every different stage. We can't do anything like that yet.

Beth Moorefield: Is there any evidence that environmental factors can influence any of these activities and actually alter patterns?

Dr. Bartolomei: That's another area of active investigation in my lab and lots of other labs. There's a whole field called Developmental Origins of Health and Disease. The idea there is that insults in utero to an embryo can be maintained or remembered and expressed later on in development. We're very interested in this hypothesis. A lot of it was originally defined by David Barker, and it was shown epidemiologically during the Dutch Hunger Winter when there was minimal caloric availability to people at that time. Women who had first-trimester babies during those times of minimal calories, these children were born and 50 years later had very high levels of heart disease and metabolic diseases. A lot of that was epidemiologically shown, but it has now been moved to animal models.

We've been very interested in this idea that very early gestational exposures may be the most dramatic. That's because that's when there's a lot of reprogramming going on. We've looked at endocrine disrupters and some assisted reproductive technologies where there're exposures in the early embryos. We use imprinted genes because for us they're our canary in the coal mine. We've shown with some of these exposures there are defects in the ability to maintain the methylation imprints or maintain other kinds of methylation, and there're defects in other kinds of reprogramming. Environmental perturbations during that early time in development can have a lasting influence on offspring. We're trying to look at that in more detail. It's another area of very active investigation as people have the capacity now to profile what's happening in the early embryo. Before we couldn't do that but now we can take small numbers of cells, look at DNA methylation, look at chromatin modifications, compare normal to environmental exposure of some kind. Science is such that we can do a lot of things that we hoped we could do 20 years ago. 


\section{$\$_{\text {CSH\& }}^{\infty}$ Cold Spring Harbor Symposia SYMPOSIA}

\section{A Conversation with Marisa Bartolomei}

Cold Spring Harb Symp Quant Biol 2017 82: 369-371 originally published online March 27, 2018 Access the most recent version at doi:10.1101/sqb.2017.82.034447

Creative This article is distributed under the terms of the

Commons http://creativecommons.org/licenses/by-nc/4.0/, which permits reuse and

License redistribution, except for commercial purposes, provided that the original author and source are credited.

Email Alerting Receive free email alerts when new articles cite this article - sign up in Service the box at the top right corner of the article or click here. 